\title{
The Use of Audio-Lingual Method in BIPA Learning for Foreign Students in West Sumatra in the Era of the Digital Revolution
}

\author{
Diana Kartika ${ }^{1}$ Endut Ahadiat ${ }^{2}$ Yuni Astuti $^{3}$ \\ ${ }^{1}$ Universitas Bung Hatta, Padang, Indonesia, \\ ${ }^{2}$ Universitas Bung Hatta, Padang, Indonesia \\ ${ }^{3}$ Universitas Negeri Padang, Indonesia \\ 1dianakartika@bunghatta.ac.id, 2endutahadiat@bunghatta.ac.id, \\ 3 yuniastuti@fik.unp.ac.id
}

\begin{abstract}
The development of BIPA learning is inseparable from the use of methods in learning. Methods are needed at every learning process and every level of education. In this era of the digital revolution, the use of Audi-Lingual methods in BIPA learning is focused on the use of technology aimed at foreign speakers who are millennials who should be packaged as attractive as possible so that students do not get bored quickly and have a high desire in learning Indonesian. In this audio-lingual method, the material presented is material by the characteristics of the students. The research method used is qualitative of foreign students in West Sumatra. Data were analyzed based on interview data and data from the results of the test in the form of multiple-choice totaling 30 items with 15 students, found that scores above 75 were $68.5 \%$, and the remainder obtained Indonesian language mastery scores below the grade 75 . Thus it can be interpreted the audio-lingual method is a method that can be used for BIPA learning of foreign student.
\end{abstract}

Keywords: Audio-Lingual, Digital, BIPA Learning, Digital Revolution

\section{PENDAHULUAN}

Perkembangan pengetahuan dan teknologi yang begitu cepat dan meluas dapat memberikan pengaruh atau dampak positif bagi bahasa Indonesia di mata dunia. Arus globalisasi sudah tidak terbendung masuk ke Indonesia dengan disertai dengan perkembangan teknologi yang semakin canggih, dunia kini memasuki era revolusi industri 4.0, yakni menekankan pada pola digital economy, artificial intelligence, big data, robotic, dan lain sebagainya atau dikenal dengan fenomena disruptive innovation [5]. Menjelaskan bahwa berdasarkan teori Skinner's Behaviorism, diasumsikan bahwa manusia dapat dilatih menggunakan sistem penguatan. Perilaku yang benar menerima umpan balik positif, sedangkan kesalahan menerima umpan balik negatif. Begitu juga halnya dengan pembelaran bahas indonesia untuk penutup asing. Menurut Saddhono, Kundharu dalam pengajaran BIPA terdapat tujuh aspek yang harus dibahas yaitu: budaya, sistem keagamaan, sistem sosial, sistem kependudukan, sistem bahasa, sistem seni dan sistem teknologi dan peralatan kehidupan [11]. Selanjutnya [14] menjelaskan bahwa tujuan dari pembelajaran untuk BIPA ini 
harus memiliki sistem yang menarik untuk memberikan penilaian dalam pembelajarannya. Berbagai macam strategi yang digunakan untuk mendapatkan penilaian ditingkat Nasional maupun International terutama pada perguruan tinggi yang memberikan peluang atau tuntutan adanya mahasiswa asing atau mahasiswa dari negara lain untuk menuntut ilmu di perguruan tinggi yang ada di Indonesia. Dengan adanya mahasiswa asing tersebut akan memberikan dampak positif bagi para pakar bahasa indonesia yang dikenal dengan istilah BIPA (Bahasa Indonesia Penutur Asing) untuk mengenalkan bahasa Indonesia kepada mahasiswa tersebut.

Hanani Nurul mengatakan bahwa mempelajari bahasa merupakan kebutuhan yang bisa dikatakan sama kunonya dengan sejarah kehidupan manusia itu sendiri. Sama halnya apabila orang Indonesia menuntut ilmu diluar negeri harus mampu berbahasa Inggris, dan begitu juga halnya dengan seluruh mahasiswa asing di Perguruan Tinggi di Indonesia juga harus mampu berbahasa Indonesia. Dikuatkan lagi dengan keluarnya Peraturan Presiden Republik Indonesia Nomor 63 tahun 2019 tentang Penggunaan Bahasa Indonesia ditetapkan pada tanggal 30 September 2019 di Jakarta oleh Presiden Bahasa Indonesia adalah bahasa resmi nasional yang digunakan di seluruh wilayah Negara Kesatuan Republik Indonesia (Hanani, 2016). Lubna Syarifa mengungkapkan bahwa semakin kuatnya posisi Negara Indonesia di pergaulan antarbangsa maka akan semakin mengukuhkan pentingnya penguasaan bahasa Indonesia bagi bangsa lain. Dengan adanya peraturan tersebut maka dapat diartikan bahwa setiap orang asing yang datang ke Indonesia harus menggunakan Bahasa Indonesia dan ini merupakan peluang bagi para ilmuan BIPA untuk mengembangkan bahasa indonesia kepada Dunia. Pada dasarnya tujuan pembelajaran BIPA yang beraneka ragam muaranya adalah kemampuan berkomunikasi dalam bahasa kedua, yaitu bahasa Indonesia oleh para pemelajar bahasa Indonesia [8]. Rahmawati Laili Etika, dkk menjelaskan bahwa kompetensi bahasa yang harus dimiliki dalam pembelajaran bahasa itu diantaranya kemampuan mendengar, kemampuan berbicara, kemampuan membaca dan kemampuan menulis [11].

Pada era revolusi digital yang hidupnya generasi millenial ini menutut para pendidik harus mampu memanfaatkan teknologi secara efektif agar pemelajar bahasa lebih menarik mengikuti pembelajaran Bipa tersebut. Dalam menghadapi generasi millinial ini dituntut kreatifitas dan inovasi-inovasi yang harus diberikan oleh pendidik karena salah satu ciri generasi millennial tersebut. [15] mengungkapkan bahwa dengan adanya Penggunaan daya dan data yang tidak terbatas mengakibatkan perkembangan internet dan teknologi digital yang masif di era revolusi industri 4.0 aakan dapat menyebabkan segala sesuatu hal menjadi tanpa batas (borderless) pada era mendisrupsi berbagai aktivitas manusia,termasuk di dalam bidang pendidikan, tanpa kecuali bidang pendidikan dan pembelajaran bahasa Indonesia. merasa cepat bosan dengan metode pembelajaran yang konvensional.

Banyak metode yang dapat digunakan dalam pembelajaran BIPA tersebut, namun penulis menilai metode yang paling cocok dalam era revolusi digital ini untuk pembelajaran bipa ini yaitu metode audiolingual karena metode ini merupakan metode yang dilakukan praktek atau latihan dalam bentuk dialog yang dapat membuat siswa mampu berbicara seperti pemilik bahasa itu sendiri. Pengembangan metode audiolingual berasal dari penggunaan metode langsung yang dirasakan masih memiliki kelemahan diantaranya pada saat menjelaskan topik yang dirasa sulit dipahami oleh siswa. Prinsip-prinsip utama metode Audio Lingual Method mengemukakan "4 slogan", yaitu (1) Bahasa adalah ujaran, bukan tulisan, (2) bahasa adalah seperangkat kebiasaan, yang artinya bahwa suatu perilaku akan menjadi kebiasaan apabila diulang berkali-kali. (3) Ajarkanlah bahasa, bukan mengenai bahasa, pelajaran bahasa harus diisi dengan kegiatan berbahasa bukan kegiatan mempelajari kaidah-kaidah bahasa, dan (4) Bahasa adalah apa yang dikatakan penutur asli, [7]. E. Alepis menjelaskan bahwa subsistem audio-visual memiliki kelebihan yang dapat digunakan dalam pengambilan keputusan dalam 
penggunaan teori yang akan digunakan dalam pembelajaran (Alepis, Stathopoulou, Virvou, \& Tsihrintzis, 2010). Donald Freeman menjelaskan bahwa pemrolehan bahasa kedua itu memerlukan artikulasi dalam proses pembelajaran yang merekonstruksikan pengalaman dalam pembelajaran praktek pelajar tersebut[3].

Karakteristik metode Audiolingual [3] ini atara lain adalah sebagai berikut: 1) dalam pengajarannya harus menguasai empat ketrampilan dalam berbahasa secara seimbang, 2) sistematika penyajiannya yaitu menyimak dan berbicara setelah itu baru membaca serta menulis, 3) kalimat bahasa asing yang diberikan yaitu dalam bentuk percakapan dengant ujuan harus dihafalkan, 4) agar dapat menguasai pola kalimat harus melakukan latihan pola (patternpratctice). Latihan atau drill mengikuti urutan: stimulus $>$ response $>$ reinfrcement, 5) Kosa kata bukan sebagai kata lepas yang berdiri sendiri namun dibatasi secara ketat atau ungkapan 6) melakukan pengajaran sistem bunyi secara berstruktur agar dapat dipraktekan oleh pelajar dengan menggunakan teknik peniruan, demonstrasi, kontras dan komparasi, kontras, 7) materi menulis merupakan representasi dari materi berbicara, yang terdiri daripola kalimat dan kosa kata secara lisan, 8) hindari penerjemahan. Penggunaan bahasa ibu dapat digunakan secara terbatas apabila diperlukan untuk memberikan penjelasan, 9) untuk gramatika tidak perlu diajarkan pada tahap permulaan. 10) materi focus pada pola yang menunjukan terdapatnya perbedaan struktural antara bahasa asing yang diajarkan dengan bahasa ibu pelajar. 11) hindari kesalahan dalam memberikan response, 12) siswa mengikuti atau merespon apa yang distimuluskan oleh guru, 13) pentingya penggunaan bahan laboratrium bahasa, rekaman dan visual aids.

Langkah-langkah penyajian audiolingual method menurut [12] yaitu: 1) dalam menyajikan dialog atau bacaan yang pendek guru harus membacanya secara berulang kali, dan agar pelajar dapat menyimak dan melihat, 2) meniru bacaan guru dengan kalimat per kalimat secara klasikal, sambil menghafalkan kalimat tersebut. Teknik ini disebut mimicry-memorization atau istilah lain disingkat mim-mem technique, 3) pola kalimat bacaan pendek, awalnya dianggap sukar, karena terdapatnya struktur dalam bahasa ibu dari pelajar, 4) Dramatisasi dialog atau bacaan pendek yang sudah dilatihkan. Pelajar memeragakan atau mendramatisasikan dialog yang sudah dihafalkan didepan kelas secara bergantian, 5) melakukan latihan dalam membuat kalimat lain yang sesuai dengan pola kalimat yang sudah dipelajari sebelumya. Terkait dengan digitalisasi daya literasi, pengajar BIPA dapat mengoptimalkan pada penggunaan teknologi informasi dan komunikasi berbasis digital dan membuka diri terhadap wawasan baru-terbarukan mengenai ilmu pengetahuan, teknologi, seni-budaya, dan bergerak dinamis mengikuti arus modernisasi dan globalisasi, [2]. Kegiatan belajar mengajar hendaknya memberikan kesempatan kepada pembelajar untuk melakukan hal Suasana belajar yang diciptakan pengajar harus melibatkan pembelajar secara aktif, [15]. Dengan demikian penelitian ini fokus melihat penggunaan audiolingual.

\section{METODE PENELITIAN}

Metode penelitian yang digunakan yaitu penelitian kualitatif dengan menggunakan teknik observasi dan wawancara. Data penelitian ini bersumber dari informasi yang diperoleh dari para pegiat BIPA yang ikut terlibat dalam program bipa tersebut serta benda dari hasil dokumentasi seperti data database pebelajar dan pengajar, serta seperangkat aturan tertulis. Alat pengumpulan data dalam penelitian ini yaitu menggunakan alat pendukung serta alat yang dapat menunjang data penelitian yakni berupa (1) penggunaan pedoman analisis dari dokumen, (2) pedoman untuk melakukan wawancara, dan (3) pedoman yang digunakan untuk observasi dilapangan. Setelah data dikumpulkan yang berupa dari hasil rekaman, dokumen, 
dan gambar maka selanjutnya dilakukan kegiatan analisis data melalui dua tahap, pertama analisis data selama pengumpulan data dan kedua melakukan analisis data setelah data terkumpul.

\section{HASIL DAN PEMBAHASAN}

Penggunaan metode audio-lingual merupakan metode yang banyak mendengar dan mengulang kembali apa yang didengar. Oleh sebab itu, penulis selalu mengulang-ulang materi yang sudah disampaikan kepada peserta didik. Penulis menyadari bahwa mahasiswa asing yang ada di Perguruan Tinggi Sumatera Barat merupakan mahasiswa yang baru mengenal Bahasa Indonesia. Pengulangan itu tidak saja diberikan di kelas, tetapi juga di luar kelas dengan bahasa yang bisa dipahami mahasiswa. Materi yang diberikan kepada peserta didik itu tentang:

1) Pengucapan Salam

Pengucapan "selamat pagi, siang, sore, dan malam" sering dipertukarkan. Setiap hari, penulis selalu mengulang-ulang di dalam kelas sesuai dengan kondisi pada saat belajar. Namun, ketika di luar kelas, penulis juga memberikan pengulangan ucapan salam, terutama pada para mahasiswa yang tinggal di asrama kampus. Di luar kelas, pengulangan justru lebih beragam karena setiap saat bertemu dengan mahasiswa selalu mengucapkan salam.

2) Perkenalan Diri

Kalimat dalam perkenalan diri ini yang diberikan penulis yaitu tentang "Nama saya..." Saya orang... "Saya berasal dari... "Saya tinggal di..../alamat rumah saya di.... " Saya mahasiswa program studi... Di Universitas...."Terimakasih. kalimat tersebut setiap pertemuan selalu dilakukan pengulangan sehingga peseta didik akan lebih mudah memahami apa yang disampaikan.

3) Pengenalan nama hari dan bulan.

Pengenalan nama hari dan bulan, dimulai dengan pertanyaan tentang tanggal lahir. Setiap siswa diminta menyebutkan tanggal, bulan, dan tahun kelahiran. Nama hari dan bulan dikenalkan dengan terjemahan bahasa Inggris

4) Pelafalan abjad

Karena pengaruh bahasa nasional, Bahasa Khmer, dan pengaruh bahasa asing, Bahasa Inggris, para mahasiswa sering melakukan kesalahan dalam pengucapan abjad. Misalnya /a/ /c/, /e/, /f/, /g/, /h/, /i/, /j/, /q/, /v/, dan /z/. Contoh abjad yang sering diulang untuk dilafalkan adalah "RPITS Takeo". Lidah para mahasiswa masih fasih mengucapkannya dalam lafal Bahasa Inggris /ar pi ai ti es/.

5) Pengucapan nama benda-benda

Ketika memperkenalkan benda-benda sekitar kita, penulis memperkenalkan benda-benda yang ada dalam buku dengan benda aslinya. Misalnya, ketika berbicara tentang nama benda di kelas, penulis memberi tahu nama benda, seperti: meja, kursi, papan tulis, spidol, penghapus, jendela, pintu, vas bunga, kipas angin, tempat sampah, dan lukisan. Benda di kamar tidur, penulis meminta para mahasiswa mengingat isi kamar tidur, seperti: tempat tidur, bantal, guling, lampu, pigura foto, dan selimut. Untuk ruang keluarga, selain meja dan kursi tamu, televisi, ada juga majalah dan surat kabar. Untuk benda-benda di dapur dan ruang makan, seperti: kompor, panci, sodet, pisau, piring, gelas, sendok, garpu, dan kulkas. Selain itu, ada juga benda-benda yang dipakai, seperti: kemeja, celana panjang, rok, sepatu, sandal jepit, topi, kalung, gelang, cincin, jam tangan, dan dasi. Benda yang sulit diterangkan namanya adalah majalah, lukisan, dan kulkas. Walaupun ada, nama 
benda-benda itu sulit diterangkan, jadi penulis perlu mencari gambar-gambar itu di internet melalui telepon genggam lalu diperlihatkan kepada mahasiswa

6) Pengenalan angka.

Untuk pengenalan kosakata angka, penulis memulai dengan tiga angka pertama, dilanjutkan lima angka pertama dan diterjemahkan dengan bahasa Khmer. Sebagai tandingannya penulis menghafalkan kosakata angka satu sampai dengan sepuluh dalam bahasa Khmer. Sama dengan pengucapan salam, kosakata angka ini diulang-ulang di dalam kelas dan di luar kelas.

Dengan demikian jelaslah bahwa pelaksanaan pembelajaran BIPA yang dilakukan sudah mengarah atau fokus kepada keterampilan dalam aspek berbahasa sehingga mudah dipahami oleh pembelajar. [17] menjelaskan bahwa apabila pemberian materi kepada pembelajaran bahasa indonesia disesuaikan dengan perkembangan yang dimiliki pembelajar dengan tujuan agar sesuai dengan perkembangan jiwa serta nalar yang dimilikinya [18].

\section{SIMPULAN}

Penggunaan metode audiolingual merupakan suatu metode yang melakukan praktek atau latihan dalam berbahasa dalam bentuk dialog atau berbicara secara interaksi langsung dan diharapkan peserta didik mampu berbicara seolah-olah pemilik bahasa itu sendiri. Dalam metode audio-lingual ini pada awalnya merupakan hasil dari evaluasi metode langsung yang memiliki kelemahan didalam memberikan penjelasan topik yang dirasa sulit dipahami oleh peserta didik itu sendiri. Berdasarkan proses pembelajaran yang diberikan kemudidan diberikan penilaian terhadap mahasiswa tersebut dengan materi tentang perkenalan diri sendiri, pemberian salam, pengenalan nama hari dan bulan, pelafalan abjad, memperkenalkan benda-benda dan pengenalan angka dengan memberikan 30 butir soal pilihan ganda dengan jumlah mahasiswa 15 orang yang mendapat nilai di atas 75 yaitu ada $68,5 \%$, dan sisanya memperoleh nilai penguasaan bahasa Indonesianya masih dibawah nilai 75 , dengan demikian dapat disimpulkan bahwa penggunaan metode audio Lingual dalam pembelajaran BIPA dapat digunakan untuk meningkatkan kemampuan berbahasa indonesia untuk mahasiswa asing yang ada di Perguruan Tinggi.

\section{REFERENCES}

[1] Alepis, E., Stathopoulou, I., Virvou, M., \& Tsihrintzis, G. A. (2010). Audio-Lingual And Visual-Facial Emotion Recognition: Towards a Bi-Modal Interaction System. International Conference on Tools with Artificial Intelligence. https://doi.org/10.1109/ICTAI.2010.111.

[2] Anggaira, A. S. (2019). Literasi Terkini Dalam Pembelajaran Bipa Pada Era Revolusi Digital. Prosiding Seminarnasional Pendidikan Programpascasarjanauniversitas Pgri Palembang, 29-39.

[3] Freeman, D. (2017). Educating Second Language Teachers. Review, 1-4.

[4] Hanani, N. (2016). Efektivitas Penggunaan Metode Audiolingual Dalam Pembelajaran Bahasa Arab. Realita, 14(2), 246-256.

[5] Maedeh Alemi, E. T. (2017). Audio Lingual Method. International Conference on Applied Research in Language Studies, 0-5.

[6] Manipuspika, Y. S. 2014. Accomplishing Coherence In Talk Shows: A Comparison Between English And Indonesian. Indonesian Journal of Applied Linguistics, Vol. 3 No.2, January 2014, pp. 154-168154 
[7] MS, S. S. U. (2016). Penerapan Metode Alm (Audio Lingual Method) Dalam Pembelajaran Speaking English Di Smp Islam An-Nidhomiyah Pamekasan. Nuansa, 13(1), 108-130.

[8] Lubna, S. (2017). Penyusunan Bahan Ajar Bahasa Indonesia Bagi Penutur Asing (Bipa) Untuk Pebelajar Anak. Tuah Talino, 11(11), 83-94.

[9] L. E. Rahmawati, S. Suwandi, K. Saddhono, B. Setiawan. 2019. Need Analysis On The Development Of Writing Competency Test For Foreign University Students. Humanities \& Social Sciences Reviews. Vol 7 No. 3.

[10] Purwokerto, I. (2017). Metode Audio Lingual (Audio-Lingual Method) Dan Penerapannya Dalam Pembelajaran Bahasa Arab. Munasib, 1(1), 77-90.

[11] Rahmawati, L. E., Suwandi, S., Saddhono, K., \& Setiawan, B. (2019). Need Analysis On The Development Of Writing Competency. Humanities \& Social Sciences Reviews, 7(3), 467-471.

[12]Saddhono, K. Aspek Budaya dalam Buku Ajar Bahasa Indonesia bagi Penutur Asing (BIPA) di Indonesia. Makalah Kongres Bahasa. Jakarta: Pusat Bahasa. (2018) .

[13] Sugiyono. 2016. Metode Penelitian Kuantitatif, Kualitatif dan R\&D. Bandung: PT Alfabet

[14] S. Sujinah, Dewi S., Sofi Y., Ngatmain, E. S. Isnah. 2019. Developing Reading Comprehension Assessment Based Adobe Flash Cc2015 For Bipa Intermediate Level. Humanities \& Social Sciences Reviews. Vol 7 No. 3.

[15] Suwandi, S. 2019. Mereduksi Benturan Kecerdasan Dalam Pembelajaran Bahasa Indonesia Di Era Revolusi Industri 4.0. Prosiding Seminar Nasional FKIP Universitas Prima Indonesia

[16] System. 22nd International Conference on Tools with Artificial Intelligence.

[17] Yani, D. (2016). Metode Audio-Lingual Dalam Pembelajaran Lingual Dalam Pembelajaran Kaiwa Audio-Lingual Method In Teaching Kaiwa. Lingua Didaktika Volume, 10(1), 9-17.

[18] K. Saddhono, A. Hasibuan, and M. I. Bakhtiar, "Facebook as A Learning Media in TISOL (Teaching Indonesian to Speakers of Other Languages) Learning to Support The Independency of Foreign Students in Indonesia," in Journal of Physics: Conference Series, 2019, vol. 1254, no. 1, p. 12061. 